\title{
Supermagnetic Storms: Hazard to Society
}

\author{
G. S. Lakhina and S. Alex
}

Indian Institute of Geomagnetism, Navi Mumbai, India

\section{B. T. Tsurutani}

NASA Jet Propulsion Laboratory, California Institute of Technology, Pasadena, California, USA

\author{
W. D. Gonzalez \\ Instituto Nacional de Pesquisas Espaciais, Sao Paulo, Brazil
}

Magnetic storms are an important component of space weather effects on Earth. Superintense magnetic storms (defined here as those with $D s t<-500 \mathrm{nT}$, where Dst stands for the disturbance storm time index that measures the strength of the magnetic storm), although relatively rare, can be hazardous to technological systems in space as well as on the ground. Such storms can cause life-threatening power outages, satellite damage, communication failures, and navigational problems. The data for such magnetic storms during the last 50 years is rather scarce. Research on historical geomagnetic storms can help to create a good database for intense and superintense magnetic storms. The superintense storm of 1-2 September 1859 is analyzed in the light of new knowledge of interplanetary and solar causes of storms gained from the space-age observations. We will discuss the results in the context of some recent intense storms and also the occurrence probability of such superstorms.

\section{INTRODUCTION}

We all know about the extreme weather events, like thunderstorms, hurricanes, cyclones, typhoons, floods, earthquakes, and tsunamis. Depending on their severity, these events can cause loss of life and property. These are the familiar natural hazards to the society. We can feel them, for example, the force of winds and rains during cyclones, shaking of the ground during the earthquakes, etc. There is

Extreme Events and Natural Hazards: The Complexity Perspective Geophysical Monograph Series 196

(C) 2012. American Geophysical Union. All Rights Reserved.

10.1029/2011GM001073 another natural hazard, which we cannot feel directly, but it can impose a great danger to the society, as it can damage the technological systems in space and on the ground. This is the space storm or magnetic storm, and it comes under the area of space weather and also space geomagnetism.

In addition to electromagnetic radiation, e.g., visible light, X-rays, UV, etc., the Sun emits continuously a stream of charged particles, called the solar wind, in all directions. Interaction of the solar wind with the geomagnetic field leads to the formation of the Earth's magnetosphere. When there are big solar eruptions, like solar flares and coronal mass ejections (CMEs), they hurl huge blobs of ionized matter in space. Since such solar ejecta move with supersonic speeds, higher than the solar wind speeds, they produce interplanetary (IP) shocks. When the IP shocks and the solar ejecta hit the magnetosphere, they produce worldwide geomagnetic 
field disturbances lasting for about half a day to several days, known as magnetic storms.

\section{MAGNETIC STORMS}

\subsection{Historical Background}

Geomagnetism, a new branch of physics at that time, was born with the publication of De Magnete by William Gilbert in 1600 A.D., proposing that the Earth acts as a great magnet [Gilbert, 1600]. That the Earth has a magnetic field was first realized by Petrus Peregrinus in 1259 A.D. Some ancient texts from Greece, China, and India mention the attracting properties of magnetic materials such as magnetite $\left(\mathrm{Fe}_{3} \mathrm{O}_{4}\right.$ : lodestone) as early as 800 B.C. The earliest form of magnetic compass using lodestone is believed to have been invented in China for navigation purposes around the first century A.D. The first map of field declination was made by Edmund Halley in the beginning of the eighteenth century. Alexander von Humboldt played an important role in the development of geomagnetism, in addition to his fundamental contributions to natural sciences.

Alexander von Humboldt and his colleague observed the local magnetic declination in Berlin, every half hour from midnight to morning, for the period starting from May 1806 until June 1807. On the night of 21 December 1806, von Humboldt observed strong magnetic deflections for six consecutive hours and noted the presence of correlated northern lights (aurora) overhead. When the aurora disappeared at dawn, the magnetic perturbations disappeared as well. From this, von Humboldt concluded that the magnetic disturbances on the ground and the auroras in the polar sky were two manifestation of the same phenomenon. Von Humbold gave this phenomenon the name "Magnetische Ungewitter" or magnetic storms [von Humboldt, 1808]. The worldwide network of magnetic observatories later confirmed that such "storms" were indeed worldwide phenomena [Schröder, 1997].

\subsection{Sunspots, Solar Flares, and Geomagnetic Activity}

Sunspots are the dark spots on the photosphere; they appear dark as their temperature is reduced compared to the surrounding area due to the strong magnetic fields embedded in them. Due to the invention of telescope and Galileo's interpretation of sunspots in 1612, a new era in solar observation started. An amateur German astronomer, S. Heinrich Schwabe, began observing the Sun and making counts of sunspots in 1826. He reported periodic behavior in spot counts of 10 years [Schwabe, 1843].

A decennial period in the daily variation of magnetic declination had been reported by Lamont from Munich in
1851 , but he did not relate it to the sunspot cycle. From his extensive studies, Sabine [1851, 1852] discovered that geomagnetic activity paralleled the recently discovered sunspot cycle.

On 1 September 1859 (Thursday) morning, Richard Carrington [1859] was studying a big group of sunspots. He was surprised by the sudden appearance of two brilliant beads of blinding white light over the sunspots, which intensified with time. Carrington later wrote, "I hastily ran to call someone to witness the exhibition with me. On returning within 60 seconds, I was mortified to find that it was already much changed and enfeebled." He and his witness watched the white spots contract to mere pinpoints and disappear. This was the first observation of the white light (visible) solar flare on record. The 1 September 1859 solar flare was also observed by R. Hodgson [1859], but somehow, it came to be known as Carrington flare.

The very next day, a severe magnetic storm was recorded by the Kew, and some other observatories, especially Colaba, Bombay. Carrington knew about the occurrence of the magnetic storm but failed to connect it to the solar flare. It took nearly 100 years to gather sufficient statistics to make a convincing case for an association between large solar flares and severe magnetic storms [Hale, 1931; Chapman and Bartels, 1940; Newton, 1943].

\section{MODERN OUTLOOK}

The solar wind is essentially a highly conducting plasma, and it obeys the simple Ohm's law of the form

$$
\mathbf{J}=\sigma(\mathbf{E}+\mathbf{V} \times \mathbf{B})
$$

where $\mathbf{J}, \mathbf{E}, \mathbf{B}, \mathbf{V}$, and $\sigma$ are the electrical current density, the electric field, the magnetic field, the flow velocity, and the electrical conductivity, respectively. For infinite conductivity, i.e., $\sigma=\infty$,

$$
\mathbf{E}+\mathbf{V} \times \mathbf{B}=0, \quad \text { or } \quad \mathbf{V}=\mathbf{E} \times \mathbf{B} / B^{2},
$$

meaning that solar magnetic field is frozen in the solar wind, and it is dragged with the flow into the interplanetary space. This is the interplanetary magnetic field (IMF). The IMF plays an important role in the transfer of energy from the solar wind into the magnetosphere and in driving the magnetic storms.

The magnetopause boundary layer is the site where solar wind energy and momentum is transferred into the magnetosphere. Two main processes by which the solar wind plasma can cross the magnetopause are (1) direct entry involving magnetic reconnection [Dungey, 1961; Gonzalez 
et al., 1989; Lakhina, 2000] and (2) the cross-field transport due to the scattering of particles by magnetopause boundary layer waves [Gurnett et al., 1979; Tsurutani et al., 1998; Lakhina et al., 2000] across the closed magnetopause field lines. The boundary layer waves provide a specific mechanism for "viscous interaction" [Axford and Hines, 1961; Tsurutani and Gonzalez, 1995] in which the solar wind flow energy is transferred to the magnetosphere. Several other processes, like impulsive penetration of the magnetosheath plasma elements with an excess momentum density, plasma entry due to solar wind irregularities [Schindler, 1979], the Kelvin-Helmholtz instability [Miura, 1987], and plasma percolation due to overlapping of a large number of tearing islands at the magnetopause have been suggested for the plasma entry across the magnetopause [Galeev et al., 1986]. All these processes, however, appear to play only a minor role in solar wind energy transfer.

Magnetic reconnection is recognized as a basic plasma process, which converts magnetic energy into plasma kinetic energy accompanied by topological changes in the magnetic field configuration. It prohibits the excessive buildup of magnetic energy in the current sheets [Dungey, 1961]. Magnetic reconnection is very effective when the IMF is directed southward leading to strong plasma injection from the tail toward the inner magnetosphere causing intense auroras at high-latitude nightside regions. About 5\% to $10 \%$ of solar wind energy is transferred into the Earth's magnetosphere [Gonzalez et al., 1989; Weiss et al., 1992] during substorms and storms. During northward IMF intervals, however, magnetic reconnection is not very effective, and the waveparticle cross-field transport may become dominant. Tsurutani and Gonzalez [1995] have estimated that only about $0.1 \%$ to
$0.3 \%$ of the solar wind energy gets transferred to the magnetosphere during northward IMFs.

A schematic of magnetic reconnection process responsible for the solar wind energy transfer in the magnetosphere is shown in Figure 1. When the IMFs are directed opposite to the Earth's fields, there is magnetic erosion on the dayside magnetosphere (by magnetic connection) and magnetic field accumulation on the nightside magnetotail region. Subsequent reconnection in the nightside magnetotail leads to plasma injection at these local times and auroras occurring at high-latitude nightside regions. As the magnetotail plasma get injected into the nightside magnetosphere, the energetic protons drift to the west and electrons to the east, forming a ring of current around the Earth. This current, called the "ring current," causes a diamagnetic decrease in the Earth's magnetic field measured at near-equatorial magnetic stations. The decrease in the equatorial magnetic field strength is directly related to the total energy of the ring current particles and, thus, is a good measure of the energetics of the magnetic storm [Dessler and Parker, 1959; Sckopke, 1966; Carovillano and Siscoe, 1973].

\subsection{Geomagnetic Storms}

A geomagnetic storm is characterized by a main phase during which the horizontal component of the Earth's lowlatitude magnetic fields are significantly depressed over a time span of one to a few hours followed by its recovery, which may extend over several days [Rostoker, 1997]. The main phase is caused by the intensified ring current, which moves closer to the Earth producing a depression in geomagnetic field $\mathrm{H}$ component. The recovery phase begins with the
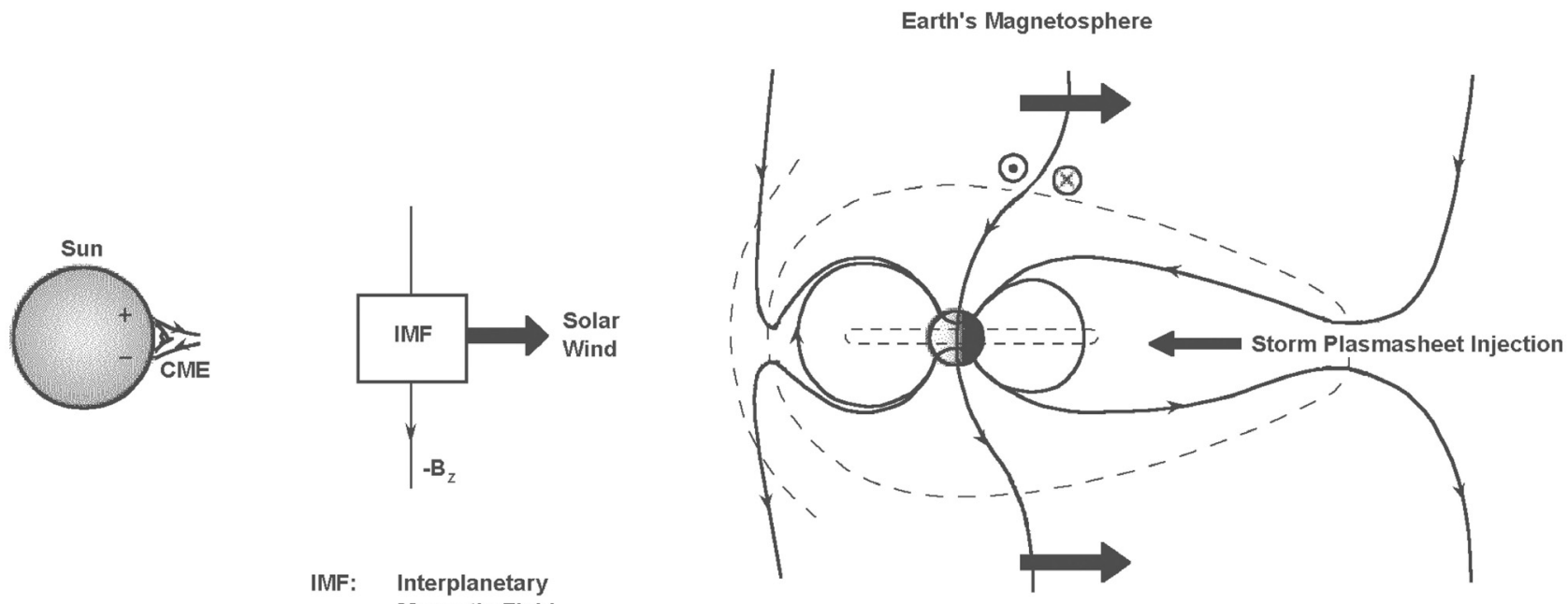

Figure 1. A schematic of the magnetic reconnection process. From Tsurutani et al. [2003]. 
decay of the ring current due to charge exchange, Coulomb collision, and wave-particle interaction processes. The auroral activity becomes intense, and auroras are not confined only to the auroral oval; rather, the auroras can be seen at the subauroral to midlatitudes. The intensity of a geomagnetic storm is expressed in terms of the disturbance storm time index $(D s t)$ or symmetric-H (SYM-H) index, which is a measure of the intensity of the ring current. Both indices are basically the same but differ in time resolution of the magnetic data used, whereas Dst is an hourly index, the SYM-H has 1 min resolution.

There are two types of geomagnetic storms. The storms that are characterized by a sudden increase in the horizontal magnetic field intensity shortly before the main phase are called sudden commencement (SC)-type storms (see top panel of Figure 2). This sudden increase in magnetic field strength is caused by the interplanetary shock compression of the magnetosphere. The period between the SC and the storm main phase is called the initial phase. However, all magnetic storms do not have an initial phase. The SC-type magnetic storms are driven by the CMEs [Gonzalez et al., 1994; Taylor et al., 1994]. On the other hand, geomagnetic storms that are not accompanied by SCs are called gradual geomagnetic storm (SG) type (bottom panel of Figure 2). The SG-type geomagnetic storms are caused by the corotating interaction regions (CIRs) associated with fast streams

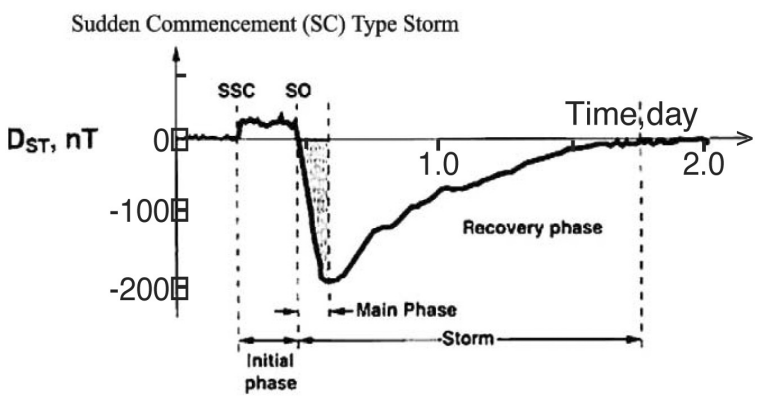

Gradual (SG) Type Storm

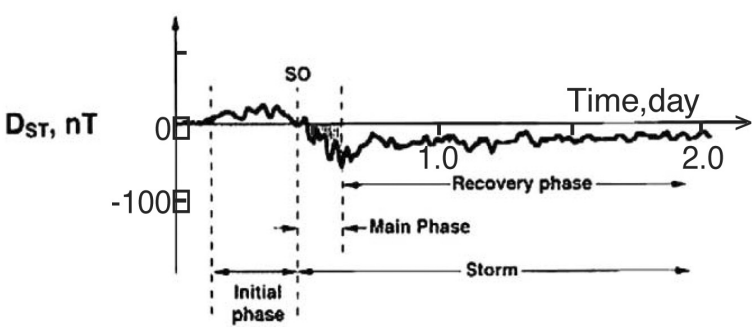

Figure 2. (top) A schematic of a sudden ... driven by an ICME and (bottom) gradual (SG) type ... by a CIR. All storms may not have initial phases. Slightly modified from Tsurutani et al. [2006] and Lakhina and Tsurutani [2011]. emanating from coronal holes [Taylor et al., 1994; Tsurutani and Gonzales, 1995; Tsurutani et al., 2006].

Both SC and SG storms are further classified into type 1 or type 2 storms. Magnetic storms having a single main phase, wherein the Dst decreases more or less continuously to a minimum value and then starts to recover, are called type 1 or one-step storms. Geomagnetic storms, where the main phase undergoes a two-step growth in the ring current [Kamide et al., 1998] in a way that before the ring current had decayed to a significant prestorm level, a new major particle injection occurs, leading to further buildup of the ring current and further decrease of Dst, are called type 2 or two-step storms. Two-step storms are caused by the compressed IMF $B_{s}$ (southward component) in the sheath region downstream of the interplanetary coronal mass ejection (ICME) shocks (first main phase) followed by the magnetic cloud field (second main phase) [Tsurutani and Gonzalez, 1997]. In general, even multistep (i.e., more than two steps) storms can sometime occur depending on the ring current injection events caused by the solar and interplanetary conditions. The intensity of the magnetic storm is measured by the Dst index at peak of the main phase. The magnetic storms are called weak when $D s t>-50 \mathrm{nT}$, moderate when $-50>$ Dst $>-100 \mathrm{nT}$, and intense when Dst $<-100 \mathrm{nT}$ [Kamide et al., 1998] and superintense when Dst $<-500 \mathrm{nT}$ [Tsurutani et al., 2003]. It is interesting to note that the number of intense (Dst $<$ $-100 \mathrm{nT}$ ) storms follow the solar cycle sunspot number, but for weak to moderate storms, there is a much smaller solar cycle dependence [Tsurutani et al., 2006]. It was found that CIRs and high-speed streams are presumably responsible for most of the weaker storms.

Tsurutani et al. [2006] also showed that the CIR-generated magnetic storms appear to have very long recovery phases compared to those driven by ICMEs. Relativistic "killer" electrons appear during "recovery" phase of the magnetic storms. These electrons pose great danger for the spacecraft. The relativistic electrons are usually detected in the inner magnetosphere during intervals of high-speed solar wind streams. The exact mechanism for relativistic electron acceleration is presently unknown. However, there are two popular mechanisms. One mechanism entails electron radial diffusion due to ultralow frequency (ULF) waves that break the particles' third adiabatic invariant [Mann et al., 2004, and references therein]. The second mechanism is based on energy diffusion by cyclotron resonant interactions of electron with chorus that breaks the particles' first adiabatic invariant [Summers et al., 2004, and references therein].

The main interplanetary causes of geomagnetic storms are the ICMEs having unusually intense magnetic fields and high solar wind speeds near the Earth and the CIRs created by the interaction of fast streams emanating from solar 
Table 1. List of Intense and Superintense Magnetic Storms From Colaba and Alibag Magnetic Observatories

\begin{tabular}{|c|c|c|c|c|c|c|}
\hline $\begin{array}{c}\text { Serial } \\
\text { Number }\end{array}$ & Year & Month & Day & $\mathrm{H}(\mathrm{nT})$ & $D s t(\mathrm{nT})$ & Remark \\
\hline 1 & 1847 & Sep & 24 & 471.0 & - & Colaba \\
\hline 2 & 1847 & Oct & 23 & 535.0 & - & Colaba \\
\hline 3 & 1848 & Nov & 17 & 404.0 & - & Colaba \\
\hline 4 & 1857 & Dec & 17 & 306.0 & - & Colaba \\
\hline 5 & 1859 & Sep & $1-2$ & 1722.0 & - & Colaba \\
\hline 6 & 1859 & Oct & 12 & 984.0 & - & Colaba \\
\hline 7 & 1872 & Feb & 4 & 1023.0 & - & Colaba \\
\hline 8 & 1872 & Oct & 15 & 430.0 & - & Colaba \\
\hline 9 & 1882 & Apr & 17 & 477.0 & - & Colaba \\
\hline 10 & 1882 & Nov & 17 & 445.0 & - & Colaba \\
\hline 11 & 1882 & Nov & 19 & 446.0 & - & Colaba \\
\hline 12 & 1892 & Feb & 13 & 612.0 & - & Colaba \\
\hline 13 & 1892 & Aug & 12 & 403.0 & - & Colaba \\
\hline 14 & 1894 & Jul & 20 & 525.0 & - & Colaba \\
\hline 15 & 1894 & Aug & 10 & 607.0 & - & Colaba \\
\hline 16 & 1903 & Oct & 31 & 819.0 & - & Colaba \\
\hline 17 & 1909 & Sep & 25 & $>1500.0$ & - & Alibag \\
\hline 18 & 1921 & May & $13-16$ & $>700.0$ & - & Alibag \\
\hline 19 & 1928 & Jul & 7 & 779.0 & - & Alibag \\
\hline 20 & 1935 & Jun & 9 & 452.0 & - & Alibag \\
\hline 21 & 1938 & Apr & 16 & 532.0 & - & Alibag \\
\hline 22 & 1944 & Dec & 16 & 424.0 & - & Alibag \\
\hline 23 & 1957 & Jan & 21 & 420.0 & -250 & Alibag \\
\hline 24 & 1957 & Sep & $4-5$ & 419.0 & -324 & Alibag \\
\hline 25 & 1957 & Sep & 13 & 582.0 & -427 & Alibag \\
\hline 26 & 1957 & Sep & 29 & 483.0 & -246 & Alibag \\
\hline 27 & 1958 & Feb & 11 & 660.0 & -426 & Alibag \\
\hline 28 & 1958 & Jul & 8 & 610.0 & -330 & Alibag \\
\hline 29 & 1960 & Apr & 1 & 625.0 & -327 & Alibag \\
\hline 30 & 1972 & Jun & 18 & 230.0 & -190 & Alibag \\
\hline 31 & 1972 & Aug & 9 & 218.0 & -154 & Alibag \\
\hline 32 & 1972 & Nov & 1 & 268.0 & -199 & Alibag \\
\hline 33 & 1980 & Dec & 19 & 479.0 & -240 & Alibag \\
\hline 34 & 1981 & Mar & 5 & 406.0 & -215 & Alibag \\
\hline 35 & 1981 & Jul & 25 & 367.0 & -226 & Alibag \\
\hline 36 & 1982 & Jul & $13-14$ & 410.0 & -325 & Alibag \\
\hline 37 & 1982 & Sep & $5-6$ & 434.0 & -289 & Alibag \\
\hline 38 & 1986 & Feb & 9 & 342.0 & -307 & Alibag \\
\hline 39 & 1989 & Mar & 13 & Loss & -589 & Alibag \\
\hline 40 & 1989 & Nov & 17 & 425.0 & -266 & Alibag \\
\hline 41 & 1991 & Mar & 24 & Loss & -298 & Alibag \\
\hline 42 & 1992 & Feb & 9 & 225.0 & -201 & Alibag \\
\hline 43 & 1992 & Feb & 21 & 304.0 & -171 & Alibag \\
\hline 44 & 1992 & May & 10 & 503.0 & -288 & Alibag \\
\hline 45 & 1998 & Sep & 25 & 300.0 & -207 & Alibag \\
\hline 46 & 2000 & Apr & 6 & 384.0 & -207 & Alibag \\
\hline 47 & 2000 & Jul & 15 & 407.0 & -288 & Alibag \\
\hline 48 & 2001 & Mar & 31 & 480.0 & -358 & Alibag \\
\hline 49 & 2001 & Apr & 11 & 332.0 & -256 & Alibag \\
\hline 50 & 2001 & Nov & 6 & 359.0 & -277 & Alibag \\
\hline
\end{tabular}

Table 1. (continued)

\begin{tabular}{llllrll}
\hline $\begin{array}{c}\text { Serial } \\
\text { Number }\end{array}$ & Year & Month & Day & H (nT) & Dst (nT) & Remark \\
\hline 51 & 2001 & Nov & 24 & 455.0 & -213 & Alibag \\
52 & 2003 & Aug & 18 & 254.0 & -168 & Alibag \\
53 & 2003 & Oct & 29 & 441.0 & -345 & Alibag \\
54 & 2003 & Oct & 30 & 506.0 & -401 & Alibag \\
55 & 2003 & Nov & 20 & 749.0 & -472 & Alibag \\
56 & 2004 & Jul & 27 & 342.0 & -182 & Alibag \\
57 & 2004 & Nov & 8 & 459.0 & -383 & Alibag \\
58 & 2005 & May & 15 & 352.0 & -263 & Alibag \\
59 & 2005 & Aug & 24 & 457.0 & -216 & Alibag \\
\hline
\end{tabular}

coronal holes with the slow solar wind streams [Tsurutani et al., 1999, 2006]. Geomagnetic storms are caused by long intervals of southward IMFs [Echer et al., 2008], which considerably enhance the transfer of energy from solar wind to the magnetosphere via magnetic reconnection process, leading to strong plasma injection from the magnetotail toward the inner magnetosphere. This leads to intense auroras at high-latitude nightside regions and at the same time intensifies the ring current, which causes a diamagnetic decrease in the Earth's magnetic field measured at nearequatorial magnetic stations [Tsurutani and Gonzalez, 1997].

Superintense magnetic storms (defined here as those with Dst $<-500 \mathrm{nT}$ ), although relatively rare, have the largest societal and technological relevance. Such storms can cause life-threatening power outages, satellite damage, and loss of low Earth-orbiting (LEO) satellites, data loss, communication failures and navigational problems, damage to power transmission lines, and corrosion of long pipelines due to strong geomagnetically induced current (GIC). The data for superintense magnetic storms are rather scarce. For example, only one truly superintense magnetic storm has been recorded (DST $=-640 \mathrm{nT}, 13$ March 1989) during the space age (since 1958).

There was a great media interest about the possible supermagnetic storms in October-November 2003. Though the solar flares on 28 and 29 October were of class X17 and X10, they failed to produce a superintense storm; they produced intense double storm of mere Dst $-400 \mathrm{nT}$ [Mannucci et al., 2005]. A much weaker solar flare (and CME) of class M3.2/2N on 18 November 2003 resulted in a near superintense storm on 20 November with Dst $-490 \mathrm{nT}$. This clearly shows that it is not only the energy of the solar flare and speed of the ejecta, which control the strength of the geomagnetic storm, but also the solar magnetic field, too, plays a critical role.

Although there is record of only one or two superintense magnetic storms during the space age, many such storms 
may have occurred many times in the last $\sim 160$ years or so when the regular observatory network came into existence. Research on historical geomagnetic storms can help to create a good database for intense and superintense magnetic storms [Lakhina et al., 2005]. From the application of knowledge of interplanetary and solar causes of storms gained from the space-age observations, to this superintense storm data set, one can deduce their possible causes and construct a database for solar ejecta.

Table 1 gives a partial chronological list of some large magnetic storms, which had occurred during the past 160 years or so. The list includes the "Remarkable Magnetic Storms" described in the works of Moos [1910] and Chapman and Bartels [1940] and "Large Magnetic Storms" in the work of Tsurutani et al. [2003]. One can see that some of the events fall under the category of superintense magnetic storms. Analysis of these events can form a very useful database for superintense storms.

\subsection{Case Study of Supermagnetic Storm of 1-2 September 1859}

The supermagnetic storm of 1-2 September 1859, which was caused by the Carrigton flare that occurred on 1 September 1859, has been discussed in detail by Tsurutani et al. [2003]. This created a lot of interest in studying the historical Carrington 1-2 September 1989 supermagnetic storm; a detailed account can be found in the special issue of Advances in Space Research, edited by Clauer and Siscoe [2006]. Tsurutani et al. [2003] used the reduced ground magnetometer data of Colaba Observatory, Mumbai, India, for the 1-3 September 1859, published papers [Carrington, 1859], auroral reports based on newspapers [Kimball, 1960], and recently obtained (space age) knowledge of interplanetary and solar causes of storms, to identify the probable causes of this superstorm. We will briefly discuss the main points concerning this superstorm.

3.2.1. Solar flare of 1 September 1859 and geomagnetic phenomena. The solar flare of 1 September 1859 was observed and reported by R. C. Carrington and R. Hodgson in 1859 in the Monthly Notices of the Royal Astronomical Society and became the best-known solar event of all times. Of particular note was the intensity of the event as quoted by Carrington [1859, p. 14], "For the brilliancy was fully equal to that of direct sunlight," and by Hodgson [1859, pp. 1516], "I was suddenly surprised at the appearance of a very brilliant star of light, much brighter than the sun's surface, most dazzling to the protected eye."

The solar flare was followed by a magnetic storm at the Earth. The time delay was $\sim 17 \mathrm{~h}$ and $40 \mathrm{~min}$ (stated in the
Carrington paper). Although Carrington carefully noted this relationship, he was cautious in his appraisal: "and that towards four hours after midnight there commenced a great magnetic storm, which subsequent accounts established to have been as considerable in the southern as in the northern hemisphere". While the contemporary occurrence may deserve noting, he would not have it supposed that he even leans toward connecting them "one swallow does not make a summer" [Carrington, 1859].

The auroras occurred globally during the magnetic storm. Kimball [1960, p. 34] has provided the most complete indexing of auroral sightings: "Red glows were reported as visible from within $23^{\circ}$ of the geomagnetic equator in both north and southern hemispheres during the display of September 1-2."

In both the United States and Europe, many fires were caused by arcing from currents induced in telegraph wires during this magnetic storm [Loomis, 1861].

3.2.2. Magnetic data of Colaba Observatory during 1-2 September 1859. During 1846-1867, the Colaba Observatory was using the magnetometers made by Thomas Grubb of Dublin for measuring declination and horizontal magnetic field components. The description of these magnetometers is provided by the Royal Society [1840, 1842]. Measurements were taken at hourly intervals $24 \mathrm{~h}$ a day. When a magnetic storm (main phase) was occurring, measurements were made at $15 \mathrm{~min}$ intervals or even less. The original readings were in units of grains and feet. The data was reduced and converted into nanotesla (nT). The final absolute values " $\mathrm{H}$ " plotted in Figure 3 are in $\mathrm{nT}$ (as converted from the cgs units) [Tsurutani et al., 2003].

The magnetogram of 1-2 September 1859 from Colaba Observatory (Figure 3 ) indicates that the storm sudden commencement (SSC) was about $120 \mathrm{nT}$, the maximum $\mathrm{H}$ component depression at Colaba was $\Delta H \approx-1600 \mathrm{nT}$, and duration of the main phase of the storm (corresponding to the plasma injection) was $\sim 1-1 / 2 \mathrm{~h}$. The location at Colaba $(\sim 12$ LT) was ideal to detect the maximum magnetic response to the storm as the ring current asymmetry effect is reduced at noon. However, based on observations from this one station, one can say that this is now the most intense magnetic storm on record. Magnetometers at high latitudes, e.g., Kew and others, were either saturated or nonoperational for this event.

We will apply the recently gained knowledge about SunEarth connection and use other related information to determine the cause of the superstorm of 1-2 September 1859.

The information that the lowest latitudes of the auroras were seen at $23^{\circ}$ [Kimball, 1960] can be used to identify the plasmapause location, which in turn was used to 
1859 Bombay Magnetic Storm

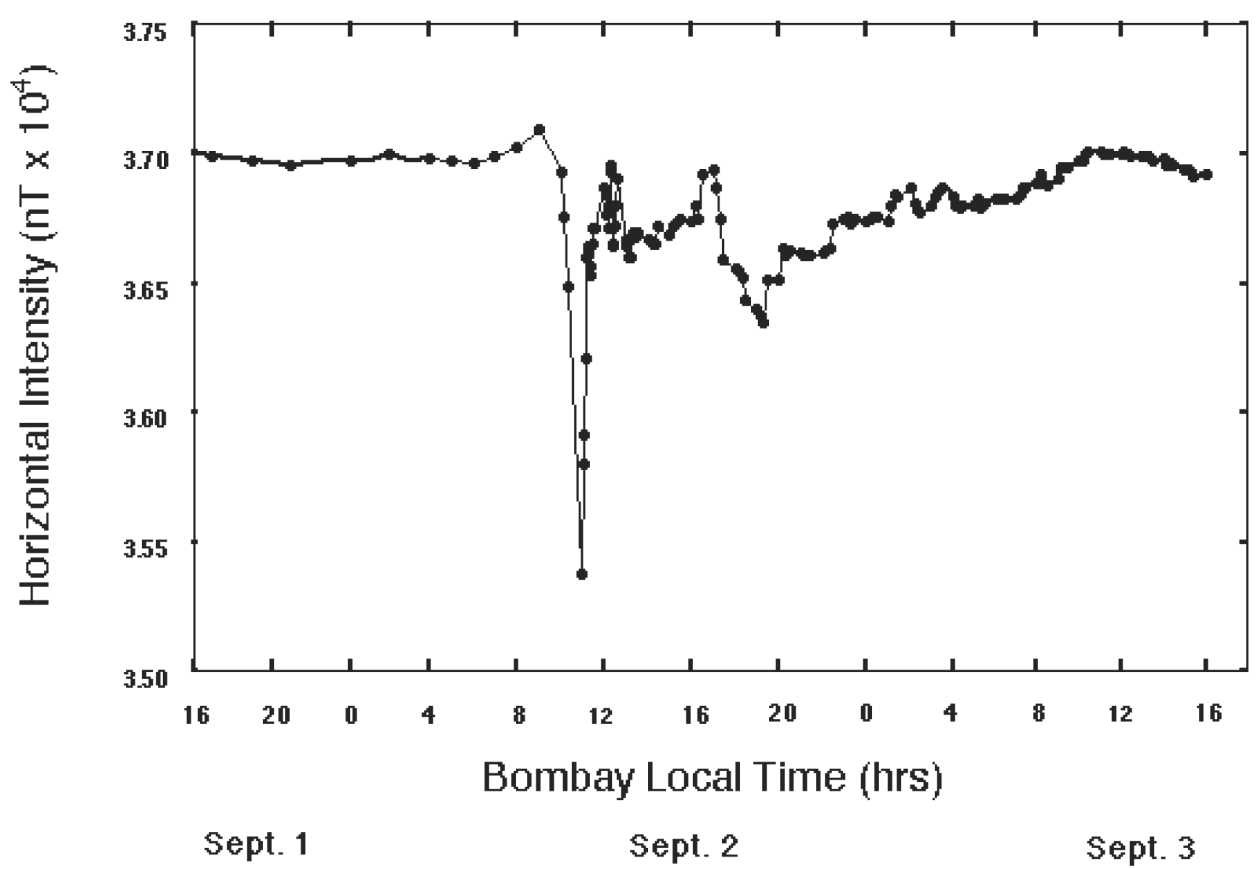

Figure 3. The Colaba (Bombay) magnetogram for the 12 September 1859 magnetic storm. From Tsurutani et al. [2003].

determine the magnetospheric convection electric fields, $E_{C} \sim 20 \mathrm{mV} \mathrm{m}^{-1}$.

Knowing that the transit time of the ICME from the Sun to the Earth was $\sim 17 \mathrm{~h}$ and $40 \mathrm{~min}$ [Carrington, 1859], an average shock transit speed of $V_{\text {shock }} \approx 2380 \mathrm{~km} \mathrm{~s}^{-1}$ is deduced. Then, using the relationships, $V_{S W}=0.775 V_{\text {shock }}$ [Cliver et al., 1990] and $B(\mathrm{nT})=0.047 V_{S W}\left(\mathrm{~km} \mathrm{~s}^{-1}\right)$ [Gonzalez et al., 1998], where $B$ is the magnetic field and $V_{S W}$ is the peak solar wind speed of the ejecta at $1 \mathrm{AU}$, the maximum possible electric field for this extremely fast interplanetary event can be expressed as [Tsurutani et al., 2003]

$$
E=2.8 \times 10^{-5} V_{\text {shock }}^{2} \mathrm{mV} \mathrm{m}^{-1}
$$

On putting $V_{\text {shock }}=2380 \mathrm{~km} \mathrm{~s}^{-1}$ in the above expression, we get the interplanetary electric field, $E_{I} \sim 160 \mathrm{mV} \mathrm{m}^{-1}$. This estimates compares well with the estimated convection electric field, $E_{C} \sim 20 \mathrm{mV} \mathrm{m}^{-1}$, if a reasonable value of the penetration efficiency of $\sim 8 \%$ of the interplanetary electric field, $E_{I}$, is assumed [Gonzalez et al., 1989].

The peak intensity or Dst index for this magnetic storm can be obtained from an empirical relation for the evolution of the ring current [Burton et al., 1975]:

$$
\frac{\mathrm{d} D s t}{\mathrm{~d} t}=Q-\frac{D s t}{\tau}
$$

where $Q$ is the energy input and $\tau$ is the decay constant for the storm time ring current. From equation (4), it follows that the Dst will attain the maximum value when there is an energy balance of the ring current, thus, giving

$$
D s t=\tau Q
$$

For very intense storms, the energy input, $Q$, can be expressed [Burton et al., 1975] as

$$
Q=1.5 \times 10^{-3}\left(V_{S W} B_{S}\right) \mathrm{nT} \mathrm{s}{ }^{-1},
$$

where $\left(V_{S W} B_{S}\right)$ is expressed in $\mathrm{mV} \mathrm{m}^{-1}$. Considering $\tau=1.5 \mathrm{~h}$ (taken from Colaba magnetogram, Figure 3), we get from equations (5) and (6), Dst $=-1760 \mathrm{nT}$, a value consistent with Colaba measurement of $\Delta H=-1600 \mathrm{nT}$ [Tsurutani et al., 2003]. We must remark here that the ring current decay time of about $2 \mathrm{~h}$ (based on Colaba data) appears to be much shorter than most storms. This short time (until the level of Dst around $-300 \mathrm{nT}$ ) is most probably related to the fast loss of particles at the magnetopause (short magnetopause distance) due to 
strong convection during the expected intense partial ring current phase. Then, from the data, it looks that a more slower and typical recovery started at about Dst of $-300 \mathrm{nT}$.

The profile of the Dst index for this storm (the first main dip) indicates that it was due to a simple plasma injection, and there is no evidence for the possibility of a complex storm. Storm main phase "compound" events or "double storms" [Kamide et al., 1998] due first to sheath fields and then to cloud fields [Tsurutani et al., 1988] can be ruled out by the (simple) storm profile. The possibility of sheath fields alone causing this superstorm can be ruled out because the compression factor of magnetic fields following fast shocks is only approximately four times [Kennel et al., 1985]. Since typical quiet interplanetary fields are $\sim 3$ to $10 \mathrm{nT}$, the compressed fields would be too low to generate the inferred interplanetary and magnetospheric electric fields for the storm. Therefore, the most likely mechanism for this intense, short duration storm would be a magnetic cloud with intense $B_{S}$ (southward) magnetic fields. The second and third depressions in Dst are caused by the new injections near the end of the fast recovery phase of the main storm, thus prolonging the recovery.

Li et al. [2006] have modeled the 1-2 September 1859 supermagnetic storm using an updated Dst prediction model of Temerin and $\mathrm{Li}$ [2002]. According to their model prediction, a very fast solar wind with a very large negative IMF $B_{z}$ can produce a supermagnetic storm with $D s t<-1600 \mathrm{nT}$, and thus, such a storm is likely to occur again. However, in the $\mathrm{Li}$ et al. [2006] model, the extremely fast recovery of the Dst requires an extremely large pressure enhancement following the shock.

3.2.3. How rare was the solar flare of 1-2 September 1859? In addition to "white light," solar flares radiate at a variety of other wavelengths as well. The energy of 1-2 September 1859 flare for the white light portion based on the observation of Carrington [1859] is estimated to be about $\sim 2 \times 10^{30}$ ergs by D. Neidig (private communication, 2001), where as the total energy of this flare is estimated to be and about $\sim 10^{32}$ ergs by K. Harvey (private communication, 2001).

On the other hand, using general scalings, Lin and Hudson [1976] have estimated the total energy of August 1972 flare as $\sim 10^{32}$ to $10^{33}$ ergs. Kane et al. [1995] has estimated the 1 June 1991 flare energy as $\sim 10^{34}$ ergs. The comparison shows that the 1 September 1859 Carrington flare was not exceptional in terms of total energy released. However, analysis of thin nitrate layers in ice cores indicates that the flux of solar energetic particles (SEPs) for Carrington event was the biggest in the last 500 years [McCracken et al., 2001a, 2001b].

\subsection{What Is the Probability of Occurrence of Supermagnetic Storms Similar to or Higher Than 1-2 September 1859?}

From the above arguments, it is clear that the 1859 flare/ CME ejecta was not unique. The 4 August 1972 flare was definitely equally or even more energetic, and the average interplanetary ejecta speed of $2850 \mathrm{~km} \mathrm{~s}^{-1}$ (with a delay time of $14.6 \mathrm{~h}$ ) was faster than that of 1859 flare ejecta [Vaisberg and Zastenker, 1976]. Actually, 4 August 1972 event had the highest transit speed on record [Cliver et al., 1990]. Yet, the accompanying magnetic storm was a moderate one with a Dst $\sim 120 \mathrm{nT}$. Unfortunately, there were no measurements for the IMF near the Earth (i.e., at 1 AU). Tsurutani et al. [1992] analyzed the Pioneer 10 (at about 2 AU) magnetic data and extrapolated it back to $1 \mathrm{AU}$. They observed that the magnetic cloud responsible for this event had its axis highly tilted from the ecliptic and had more or less northward $B_{z}$ during its passage past the Earth. Had the magnetic cloud associated with 4 August 1972 solar flare ejecta had its axis on the ecliptic or had an opposite orientation (i.e., a large southward $B_{z}$ ), the resulting storm at the Earth would have been as intense as the 1-2 September 1859 event or perhaps even more [Gonzalez et al., 2011].

Therefore, it is likely that 1859 , like supermagnetic storms, can occur again in the near future. How often can they occur? Are even more intense events possible? Can one assign probabilities to the occurrence of a similar storm or to a greater intensity storm? At this stage, it is difficult to answer these questions. To answer the first question, the one big flare per solar cycle (11 years) has the potential for creating a storm with an intensity similar to the 1859 storm. However in reality, we know that this was the largest storm in the last 150 years (about 14 solar cycles). The predictability of similar or greater intensity events require knowledge of two things: full understanding of the physical processes involved in the phenomenon and good empirical statistics of the tail of the energy distribution. If one knows the physical processes causing solar flares or magnetic storms, then the high energy tail (extreme event) distributions could be readily ascertained. Since we do not fully understand these specific saturation processes, it is therefore not known whether flares with energy $>10^{34}$ ergs or magnetic storms with $D s t<-1760$ nT are possible or not.

Can one use statistics to infer the probabilities of flares with energies less than, but close to, $10^{34}$ ergs and storms with $D s t<-1760 \mathrm{nT}$ ? Unfortunately, not with any accuracy. Even assuming that there are no major internal changes in the Sun or the magnetosphere ("stationarity," in a statistical sense), one easily notes that the statistics for extreme solar flares with energies greater than $10^{32}$ ergs and extreme magnetic storms with $D s t<-500 \mathrm{nT}$ are poor. The shapes of 
these high-energy tails are essentially unknown. One can therefore assign accurate probabilities to flares and storms for only the lower energies where the number of observed events is statistically significant.

Willis et al. [1997] have applied extreme-value statistics to the first, second, and third largest geomagnetic storms per solar cycle for 14 solar cycles (1844-1993) using the daily $a a$ index. They predict a $99 \%$ probability that the daily $a a$ index will satisfy the condition $a a<550$ for the largest geomagnetic storm in the next 100 solar cycles.

Recently, it is found that the previously thought "upper limit" of $10^{32}$ ergs for the energy of a flare can be broken by a wide margin [Kane et al., 1995]. Quite possibly, we may have not detected events at the saturation limit (either flares or magnetic storms) during the short span of only hundreds of years of observations.

It is debateable whether the Sun has had flares at superflare energy (approximately $10^{38}-10^{39}$ ergs) levels? Most probably not [Lingenfelter and Hudson, 1980], but perhaps $10^{35}$ ergs is feasible for our Sun. By using probabilistic approach, Yazev and Spirina [2009] have estimated the occurrence of superflares of $10^{36} \mathrm{erg}$ (Wolf sunspot 400) to be once in every $10^{4}$ years.

\section{INTENSE MAGNETIC STORM AND SOCIETY}

Modern society is becoming ever increasingly dependent on space technology for daily routine functions, such as communication, navigation, data transmission, global surveillance of resource surveys, atmospheric weather, etc. Space weather refers to conditions on the Sun and in the solar wind, magnetosphere, ionosphere, and thermosphere that can influence the performance and reliability of spaceborne and ground-based technological systems and can endanger human life or health.

Intense and superintense geomagnetic storms create hostile space weather conditions that can generate many hazards to the spacecraft as well as technological systems on the ground. Geomagnetic storms can cause life-threatening power outages such as the Hydro Quebec power failure during March 1989 magnetic storm. Orders of magnitude relativistic electron flux increases are observed in the radiation belts during intense magnetic storms; they can lead to malfunctioning and failure of satellite instruments due to deep dielectric charging. During the past decade alone, many magnetospheric satellites malfunctioned for several hours or even were permanently damaged due to adverse space weather conditions during intense geomagnetic storms. Strong GICs produced by sudden short-period variations in the geomagnetic field during intense magnetic storms can damage power transmission lines and corrode long pipelines. Intense and superintense geomagnetic storms produce disturbances in the ionosphere- thermosphere system that can cause communication failure and navigational errors. Heating and subsequent expansion of the thermosphere during such storms could produce extra drag [Tsurutani et al., 2007] on the LEO satellites that could reduce their lifetimes significantly. Superintense geomagnetic storms like the 1-2 September 1859 event, if they were to occur today, would produce adverse space weather conditions on a much larger scale than the intense storm of March 1989 with catastrophic consequences for the society.

\section{SUMMARY}

Intense and superintense magnetic storms are caused by the solar ejecta (due mainly to CMEs) having unusually intense magnetic fields (with large southward component) and high solar wind speeds near the Earth. However, no strong relationship between the strengths of the flares and the speed and magnetic intensities of the ICMEs has been found, yet it is certainly noted that the most intense magnetic storms are indeed related to intense solar flares, i.e., the two phenomena have a common cause, that is, magnetic reconnection at the Sun. At this stage (see discussion under Section 3.3), it is not possible to make any accurate prediction of a supermagnetic storm having similar or higher intensity than that of 1-2 September 1859.

\section{GLOSSARY}

Chorus: A right-hand, circularly polarized electromagnetic plane whistler mode wave. Chorus is generated close to the geomagnetic equatorial plane or in minimum B field pockets in the Earth's magnetosphere by the loss cone instability due to anisotropic $\sim 10$ $-100 \mathrm{keV}$ electrons. Dayside chorus is a bursty emission composed of rising frequency "elements" with duration of $\sim 0.1$ to $1.0 \mathrm{~s}$. Each element is composed of coherent subelements with durations of $\sim 1$ to $100 \mathrm{~ms}$ or more. It is believed that cyclotron resonant interaction of high-energy electrons with chorus emission can accelerate them to relativistic energies.

Coronal mass ejection (CME): A transient outflow of plasma from or through the solar corona. CMEs are often, but not always, associated with erupting prominences, disappearing solar filaments, and solar flares. CMEs usually occur in large-scale closed coronal structures. The average mass and energy of the material ejected during CME can be a few times $10^{15} \mathrm{~g}$ and $10^{31} \mathrm{erg}$.

Dst index: Disturbance storm time that measures variation in the geomagnetic field due to the equatorial ring current. It is computed from the $\mathrm{H}$ components at approximately four near-equatorial stations at hourly intervals.

Geomagnetically induced currents (GIC): Currents produced because of rapid temporal changes of the geomagnetic field during 
magnetic storms in technological conductor systems such as power grids or pipelines.

Interplanetary coronal mass ejection (ICME): Interplanetary counterpart of CME.

Photosphere: Lowest layer of the solar atmosphere. It is essentially the solar "surface" that we see when we look at the Sun in "white" (i.e., regular or visible) light. The photosphere is not a solid surface but consists of a layer of hydrogen and helium gas about $100 \mathrm{~km}$ thick. It is the site of sunspots and solar flares.

Solar ejecta: A transient outflow of material from the Sun, which propagates out from the Sun and generates major interplanetary and magnetospheric effects. The ejecta can be produced from solar flares, coronal mass ejections, erupting prominences, etc. The velocity of the ejecta in the solar atmosphere can be less than $100 \mathrm{~km}$ $\mathrm{s}^{-1}$ to greater than $1000 \mathrm{~km} \mathrm{~s}^{-1}$.

Solar flare: A sudden eruption of magnetic energy release in the solar atmosphere lasting from minutes to hours, accompanied by bursts of electromagnetic radiation and charged particles. Solar flares occur near complex sunspots. Solar flares are classified according to their X-ray brightness in the wavelength range 1 to $8 \AA$. There are three categories: $\mathrm{X}$-class flares are big with $I>10^{-4} \mathrm{~W} \mathrm{~m}^{-2}$, M-class flares are medium-sized with $10^{-5} \leq I<10^{-4} \mathrm{~W} \mathrm{~m}^{-2}$, and C-class flares are small with $10^{-6}$ $\leq I<10^{-5} \mathrm{~W} \mathrm{~m}^{-2}$, where $I$ denotes the peak X-ray burst intensity measured at the Earth. Each category for X-ray flares has nine subdivisions ranging from, e.g., $\mathrm{X} 1$ to $\mathrm{X} 9, \mathrm{M} 1$ to $\mathrm{M} 9$, and $\mathrm{C} 1$ to $\mathrm{C}$.

Symmetric-H (SYM-H) index: Same as Dst but computed at a higher resolution of $1 \mathrm{~min}$ instead of $1 \mathrm{~h}$ used for Dst.

Ultralow frequency (ULF) waves: That portion of the radio frequency spectrum from approximately $1 \mathrm{mHz}$ to $30 \mathrm{~Hz}$. They are produced by a variety of plasma processes occurring in the magnetosphere and the solar wind.

Acknowledgments. GSL thanks the Indian National Science Academy, New Delhi, for the support under the Senior Scientist scheme. Portions of this research were performed at the Jet Propulsion Laboratory, California Institute of Technology, under contract with NASA.

\section{REFERENCES}

Axford, W. I., and C. O. Hines (1961), A unifying theory of highlatitude geophysical phenomena and geomagnetic storms, Can. J. Phys., 39, 1433-1464.

Burton, R. K., R. L. McPherron, and C. T. Russell (1975), An empirical relationship between interplanetary conditions and Dst, J. Geophys. Res., 80(31), 4204-4214.
Carovillano, R. L., and G. L. Siscoe (1973), Energy and momentum theorems in magnetospheric processes, Rev. Geophys., 11(2), 289-353.

Carrington, R. C. (1859), Description of a singular appearance seen in the Sun on September 1, 1859, Mon. Not. R. Astron. Soc., 20, 13-15.

Chapman, S., and J. Bartels (1940), Geomagnetism, vol. 1, pp. 328-337, Oxford Univ. Press, New York.

Clauer, C. R., and G. Siscoe (Eds.) (2006), The Great Historical Geomagnetic Storm of 1859: A Modern Look, Adv. Space Res., $38,274 \mathrm{pp}$.

Cliver, E., J. Feynman, and H. Garrett (1990), An estimate of the maximum speed of the solar wind, 1938-1989, J. Geophys. Res., 95(A10), 17,103-17,112.

Dessler, A. J., and E. N. Parker (1959), Hydromagnetic theory of magnetic storms, J. Geophys. Res., 64(12), 2239-2252.

Dungey, J. W. (1961), Interplanetary magnetic field and the auroral zones, Phys. Res. Lett., 6, 47-48.

Echer, E., W. D. Gonzalez, B. T. Tsurutani, and A. L. C. Gonzalez (2008), Interplanetary conditions causing intense geomagnetic storms $(D s t \leq-100 \mathrm{nT})$ during solar cycle 23 (1996-2006), J. Geophys. Res., 113, A05221, doi:10.1029/2007JA012744.

Galeev, A. A., M. M. Kuznetsova, and L. M. Zelenyi (1986), Magnetopause stability threshold for patchy reconnection, Space Sci. Rev., 44, 1-41.

Gilbert, W. (1600), De Magnete, Chiswick, London, U. K. [English translation by P. F. Mottelay, Dover, New York, 1958.]

Gonzalez, W. D., B. T. Tsurutani, A. L. C. Gonzalez, E. J. Smith, F. Tang, and S. I. Akasofu (1989), Solar wind-magnetosphere coupling during intense magnetic storms (1978-1979), J. Geophys. Res., 94(A7), 8835-8851.

Gonzalez, W., J. Joselyn, Y. Kamide, H. Kroehl, G. Rostoker, B. Tsurutani, and V. Vasyliunas (1994), What is a geomagnetic storm?, J. Geophys. Res., 99(A4), 5771-5792.

Gonzalez, W. D., A. L. C. de Gonzalez, A. Dal Lago, B. T. Tsurutani, J. K. Arballo, G. S. Lakhina, B. Buti, C. M. Ho, and S.-T. Wu (1998), Magnetic cloud field intensities and solar wind velocities, Geophys. Res. Lett., 25(7), 963-966.

Gonzalez, W. D., E. Echer, A. L. Clade Gonzalez, B. T. Tsurutani, and G. S. Lakhina (2011), Extreme geomagnetic storms, recent Gleissberg cycles and space era-superintense storms, J. Atmos. Sol. Terr. Phys., 73(11-12), 1447-1453, doi:10.1016/j.jastp. 2010.07.023.

Gurnett, D., R. Anderson, B. Tsurutani, E. Smith, G. Paschmann, G. Haerendel, S. Bame, and C. Russell (1979), Plasma wave turbulence at the magnetopause: Observations from ISEE 1 and 2, J. Geophys. Res., 84(A12), 7043-7058.

Hale, G. E. (1931), The spectrohelioscope and its work. Part III. Solar eruptions and their apparent terrestrial effects, Astrophys. $J ., 73,379-412$.

Hodgson, R. (1859), On a curious appearance seen in the Sun, Mon. Not. R. Astron. Soc., 20, 15-16.

Kamide, Y., N. Yokoyama, W. Gonzalez, B. Tsurutani, I. Daglis, A. Brekke, and S. Masuda (1998), Two-step development of geomagnetic storms, J. Geophys. Res., 103(A4), 6917-6921. 
Kane, S. R., K. Hurley, J. M. McTiernan, M. Sommer, M. Boer, and M. Niel (1995), Energy release and dissipation during giant solar flares, Astrophys. J., 446, L47-L50.

Kennel, C. F., J. P. Edmiston, and T. Hada (1985), A quarter century of collisionless shock research, in Collisionless Shocks in the Heliosphere: A Tutorial Review, Geophys. Monogr. Ser., vol. 34, edited by R. G. Stone and B. T. Tsurutani, pp. 1-36, AGU, Washington, D. C., doi:10.1029/GM034p0001.

Kimball, D. S. (1960), A study of the aurora of 1859, Sci. Rep. 6, $U A G-R 109$, Univ. of Alaska Fairbanks, Fairbanks.

Lakhina, G. S. (2000), Magnetic reconnection, Bull. Astron. Soc. India, 28, 593-646.

Lakhina, G. S., and B. T. Tsurutani (2011), Electromagnetic pulsations and magnetic storms, in Encyclopedia of Solid Earth Geophysics, 2nd ed., edited by H. K. Gupta, pp. 792-796, Springer, New York.

Lakhina, G. S., B. Tsurutani, H. Kojima, and H. Matsumoto (2000), "Broadband" plasma waves in the boundary layers, J. Geophys. Res., 105(A12), 27,791-27,831.

Lakhina, G. S., S. Alex, B. T. Tsurutani, and W. D. Gonzalez (2005), Research on historical records of geomagnetic storms, in Coronal and Stellar Mass Ejections: Proceedings of the 226th Symposium of the International Astronomical Union held in Beijing, China, September 13-17, 2004, edited by K. P. Dere, J. Wang and Y. Yan, pp. 3-15, Cambridge Univ. Press, Cambridge, U. K.

Li, X., M. Temerin, B. T. Tsurutani, and S. Alex (2006), Modeling of 1-2 September 1859 super magnetic storm, Adv. Space Res., $38,273-279$.

Lin, R. P., and H. S. Hudson (1976), Non-thermal processes in large solar flares, Sol. Phys., 50, 153-178.

Lingenfelter, R. E., and H. S. Hudson (1980), Solar particle fluxes and the ancient Sun, in The Ancient Sun: Fossil Record in the Earth, Moon and Meteorites, edited by R. O. Pepin, J. A. Eddy and R. B. Merrill, pp. 69-79, Pergamon, New York.

Loomis, E. (1861), On the great auroral exhibition of Aug. 28th to Sept. 4, 1859, and on auroras generally, Am. J. Sci., 82, 318-335.

Mann, I. R., T. P. O'Brien, and D. K. Milling (2004), Correlations between ULF wave power, solar wind speed, and relativistic electron flux in the magnetosphere: Solar cycle dependence, J. Atmos. Sol. Terr. Phys., 66, 187-198.

Mannucci, A. J., B. T. Tsurutani, B. A. Iijima, A. Komjathy, A. Saito, W. D. Gonzalez, F. L. Guarnieri, J. U. Kozyra, and R. Skoug (2005), Dayside global ionospheric response to the major interplanetary events of October 29-30, 2003 "Halloween Storms", Geophys. Res. Lett., 32, L12S02, doi:10.1029/2004GL 021467.

McCracken, K., G. Dreschhoff, E. Zeller, D. Smart, and M. Shea (2001a), Solar cosmic ray events for the period 1561-1994 1. Identification in polar ice, 1561-1950, J. Geophys. Res., 106(A10), 21,585-21,598.

McCracken, K., G. Dreschhoff, D. Smart, and M. Shea (2001b), Solar cosmic ray events for the period 1561-1994 2. The Gleissberg periodicity, J. Geophys. Res., 106(A10), 21,599-21,609.
Miura, A. (1987), Simulation of the Kelvin-Helmholtz instability at the magnetopheric boundary, J. Geophys. Res., 92(A4), 31953206 .

Moos, N. A. F. (1910), Magnetic observations made at the government observatory, Bombay, for the period 1846-1905, and their discussion. Part II: The phenomenon and its discussion, Gov. Cent. Press, Bombay, India.

Newton, H. W. (1943), Solar flares and magnetic storms, Mon. Not. R. Astron. Soc., 103, 244-257.

Rostoker, G., E. Friedrich, and M. Dobbs (1997), Physics of magnetic storms, in Magnetic Storms, Geophys. Monogr. Ser., vol. 98, edited by B. T. Tsurutani et al., pp. 149-160, AGU, Washington, D. C., doi:10.1029/GM098p0149.

Royal Society (1840), Report of the Committee of Physics, Including Meteorology on the Objects of Scientific Inquiry in Those Sciences, J. E. Taylor, London, U. K.

Royal Society (1842), Revised Instructions for the Use of the Magnetic Meteorological Observations and for Magnetic Surveys, Comm. of Phys. and Meteorol., R. Soc., London, U. K.

Sabine, E. (1851), On periodical laws discoverable in mean effects on the larger magnetic disturbances, Philos. Trans. R. Soc. London, 141, 123-139.

Sabine, E. (1852), On periodical laws discoverable in mean effects on the larger magnetic disturbances, II, Philos. Trans. R. Soc. London, 142, 103-129.

Schindler, K. (1979), On the role of irregularities in plasma entry into the magnetosphere, J. Geophys. Res., 84(A12), 72577266.

Schröder, W. (1997), Some aspects of the earlier history of solarterrestrial physics, Planet. Space Sci., 45, 395-400.

Schwabe, S. H. (1843), Solar observations during 1843, Astron. Nachr., 20(495), 234-235.

Sckopke, N. (1966), A general relation between the energy of trapped particles and the disturbance field near the Earth, J. Geophys. Res., 71, 3125-3130.

Summers, D., C. Ma, N. P. Meridith, R. B. Horne, R. M. Thorne, and R. R. Anderson (2004), Modeling outer-zone relativistic electron response to whistler mode chorus activity during substorms, J. Atmos. Sol. Terr. Phys., 66, 133-146.

Taylor, J. R., M. Lester, and T. K. Yeoman (1994), A superposed epoch analysis of geomagnetic storms, Ann. Geophys., 12, 612624.

Temerin, M., and X. Li (2002), A new model for the prediction of Dst on the basis of the solar wind, J. Geophys. Res., 107(A12), 1472, doi:10.1029/2001JA007532.

Tsurutani, B. T., and W. D. Gonzalez (1995), The efficiency of "viscous interaction" between the solar wind and the magnetosphere during intense northward IMF events, Geophys. Res. Lett., 22(6), 663-666.

Tsurutani, B. T., and W. D. Gonzalez (1997), The Interplanetary causes of magnetic storms: A review, in Magnetic Storms, Geophys. Monogr. Ser, vol. 98, edited by B. T. Tsurutani et al., pp. 77-89, AGU, Washington, D. C., doi:10.1029/GM098p0077. 
Tsurutani, B. T., W. D. Gonzalez, F. Tang, S. I. Akasofu, and E. J. Smith (1988), Origin of interplanetary southward magnetic fields responsible for major magnetic storms near solar maximum (1978-1979), J. Geophys. Res., 93(A8), 8519-8531.

Tsurutani, B. T., W. D. Gonzalez, F. Tang, Y. T. Lee, M. Okada, and D. Park (1992), Reply to L. J. Lanzerotti: Solar wind RAM pressure corrections and an estimation of the efficiency of viscous interaction, Geophys. Res. Lett., 19(19), 1993-1994.

Tsurutani, B. T., G. S. Lakhina, C. M. Ho, J. K. Arballo, C. Galvan, A. Boonsiriseth, J. S. Pickett, D. A. Gurnett, W. K. Peterson, and R. M. Thorne (1998), Broadband plasma waves observed in the polar cap boundary layer: Polar, J. Geophys. Res., 103(A8), $17,351-17,366$.

Tsurutani, B. T., Y. Kamide, J. K. Arballo, W. D. Gonzalez, and R. P. Lepping (1999), Interplanetary causes of great and superintense magnetic storms, Phys. Chem. Earth, 24, 101-105.

Tsurutani, B. T., W. D. Gonzalez, G. S. Lakhina, and S. Alex (2003), The extreme magnetic storm of 1-2 September 1859, J. Geophys. Res., 108(A7), 1268, doi:10.1029/2002JA009504.

Tsurutani, B. T., et al. (2006), Corotating solar wind streams and recurrent geomagnetic activity: A review, J. Geophys. Res., 111, A07S01, doi:10.1029/2005JA011273.

Tsurutani, B. T., O. P. Verkhoglyadova, A. J. Mannucci, T. Araki, A. Sato, T. Tsuda, and K. Yumoto (2007), Oxygen ion uplift and satellite drag effects during the 30 October 2003 daytime superfountain event, Ann. Geophys., 25, 569-574.
Vaisberg, O. L., and G. N. Zastenker (1976), Solar wind and magnetosheath observations at Earth during August 1972, Space Sci. Rev., 19, 687-702.

von Humboldt, A. (1808), Die vollständigste aller bisherigen Beobachtungen über den Einfluss des Nordlichts auf die Magnetnadel, Ann. Phys., 29, 425-429.

Weiss, L. A., P. H. Reiff, J. J. Moses, and B. D. Moore (1992), Energy dissipation in substorms, in Substorms 1, Eur. Space Agency Spec. Publ., ESA SP-335, 309-317.

Willis, D. M., P. R. Stevens, and S. R. Crothers (1997), Statistics of the largest geomagnetic storms per solar cycle (1844-1993), Ann. Geophys., 15, 719-728.

Yazev, S. A., and E. A. Spirina (2009), The probabilistic approach to estimating the origination of certain types of extreme solar events, Geomagn. Aeron., 49, 898-903, doi:10.1134/S0016793 209070123.

S. Alex and G. S. Lakhina, Indian Institute of Geomagnetism, Plot No. 5, Sector-18, New Panvel (W), Navi Mumbai 410 218, India. (lakhina@iigs.iigm.res.in; salex@iiigs.iigm.res.in)

W. D. Gonzalez, Instituto Nacional de Pesquisas Espaciais, Caixa Postal 515, 12200 Sao Jose Dos Campos, Sao Paulo, Brazil. (Gonzalez@dge.inpe.br)

B. T. Tsurutani, NASA Jet Propulsion Laboratory, California Institute of Technology, Pasadena, CA 91109, USA. (bruce. tsurutani@jpl.nasa.gov) 